\title{
Genetic Control of the Immune Response in Mice: V. Minor Genes Involved in the Response to H-Y and Ea-1 Antigens
}

\author{
David L. Gasser ${ }^{1}$ and Donald C. Shreffler² \\ ${ }^{1}$ Department of Human Genetics, University of Pennsylvania, School of Medicine \\ Philadelphia, Pennsylvania \\ and \\ ${ }^{2}$ Department of Human Genetics, University of Michigan Medical School, \\ Ann Arbor, Michigan
}

Received January 8, 1974

\begin{abstract}
Murine responses to both the male specific histocompatibility antigen $\mathrm{H}-\mathrm{Y}$ and the erythrocyte alloantigen $\mathrm{Ea}-\mathrm{l}$ are regulated by genetic factors. In each case a single major gene that controls the immune response has been identified, but additional modifying factors can be demonstrated if appropriate strain combinations are studied. A single gene controlling the response to $\mathrm{Ea}-1$ antigens, which segregates when strains YBR and B10.D2 are crossed, has been shown not to be an allele of the $I r-2$ locus. A new phenomenon has also been observed in the control of anti-Ea-1 antibody production in that the mating of two responding strains, YBR and HTG, produces an $F_{1}$ generation of complete nonresponders. By linkage tests it was shown that the responding strain HTG possesses the nonresponder allele at the Ir-2 locus, so there appear to be recessive genes in the background which are able to overcome the suppressive influence of this allele.
\end{abstract}

\section{Introduction}

The discovery of immune response (Ir) genes that control reactivity to specific antigens has depended upon experiments in which the immunological system is challenged with antigens possessing highly restricted heterogeneity and specificity 
(Benacerraf et al. 1971). One means of achieving this is to challenge the host with weak native antigens which differ but slightly from corresponding host proteins (Benacerraf et al. 1971). Two antigenic systems that have been particularly useful in this approach are the H-Y histocompatibility antigen and the Ea-1 erythrocyte alloantigens. In each of these cases the host's immunologic response is controlled not only by a single major gene, but by minor genetic factors as well. We now report our results of an analysis of these minor factors.

The ability of female mice to reject skin grafts from males of the same strain is largely determined by a gene closely linked to the $H-2$ complex (Gasser and Silvers 1971a; Bailey and Hoste 1971; Bailey 1971), aithough it has been shown that background genes also influence this response (Gasser and Silvers 1971b).

In an attempt to identify the specific site within the $H-2$ complex responsible for this response, Bailey (1971) transplanted male skin onto females of several strains possessing recombinant $H-2$ chromosomes. $H-2^{b}\left(K^{\mathrm{b}} D^{\mathrm{b}}\right)$ strains were reported to produce an "extra early" response to the H-Y antigen, while $H-2^{a}(K \mathrm{k} D \mathrm{~d})$ strains gave an intermediate response. Mice possessing the $H \cdot 2^{h}\left(K^{\mathrm{d}} D^{\mathrm{b}}\right)$ haplotype produced a response comparable to that of $H-2^{a}$ strains and $H-2^{i}\left(K^{\mathrm{b}} D^{\mathrm{k}}\right)$ mice gave a response similar to that of $\mathrm{H}-2^{b}$ animals. These results suggested that the response to male skin is controlled by a gene within the $K$ region or closely linked to it. If this hypothesis is correct, rejection of male skin could be controlled by the $I r-1$ locus.

Results with the HTG strain however, were not compatible with this conclusion. These mice possess the $H-2 g$ haplotype, which is believed to consist of $H-2 K^{d} I r d H-2 D^{b}$ alleles, but their response to male skin was like that of $H-2^{b}$ mice. This finding indicates that (a) the genetic background is responsible for the rapio rejection of male skin by HTG mice, (b) the $H-2 g$ haplotype consists of something other than the $H-2 K^{d} I r d H-2 D^{b}$ alleles, or (c) there is a second immune response gene involved in male skin rejection either within the $H-2 D$ region or distally linked to it. Because of the potential importance of the last named possibility, we reexamined the genetic basis of male skin rejection by HTG females. Our results suggest that the relatively good response of strain HTG can be attributed to one or more genes not linked to $H-2$.

When the responding strain YBR is crossed with either of two nonresponding strains, BALB or CBA, the ability to produce agglutinating antibodies to Ea-1 antigens is transmitted as a single gene recessive trait (Gasser 1969). The locus controlling this trait has been designated $I r$ - 2 and maps in the fifth linkage group, which is now known to be the second chromosome. But when YBR is crossed with the poorly responding strain $\mathrm{C} 57 \mathrm{BL} / 10$ (B10), responsiveness is transmitted as a dominant trait and is determined by more than one gene (Gasser 1970). One of the $I r$ genes that segregates in this mating is linked to the H-2 complex (Gasser and Shreffler 1972). A second gene that segregates in the same mating can be studied by crossing YBR with the congenic strain B10.D2, which possesses the same $H$-2 allele as YBR, $H-2^{d}$ but the genetic background of B10 (Gasser and Shreffler 1972). We have now shown by a linkage test that this gene is not an allele of the $I r-2$ locus.

The inbred strain HTG has now been shown to be a responder to $E a-1$ antigens, but when this strain was crossed with another responder strain, YBR, the $F_{1}$ hybrids were all nonresponders. Linkage tests demonstrated that HTG possesses the nonresponder allele at the $I r-2$ locus, so these mice apparently possess other genes that are able to overcome the influence of this locus. 


\section{Materials and Methods}

Animals. The origin of the YBR strain has been described (Gasser 1969). Strains B10, B10.D2/new (B10.D2) and HTG were obtained from The Jackson Laboratory, Bar Harbor, Maine.

H-2 Typing. $H-2$ typing was performed by both the PVP hemagglutination technique and by the cytotoxic absorption method (David and Shreffler 1972).

Skin Grafting. The grafting technique of Billingham (1961) was employed and skin grafts were inspected frequently thrcughout a 100-day observation period.

Immunization and Antibody Assay. The methods for obtaining antibody to $\mathrm{Ea}-\mathrm{I}$ and assaying its activity were the same as previously described (Gasser 1969).

\section{Results}

Rejection of Male Skin by HTG Females. Although our grafting technique differed from Bailey's method (Bailey 1971), we confirmed his observation that HTG mice respond to male skin more effectively than do B10.D2 $\left(H-2^{d}\right)$ mice (Table 1$)$. However, our experiments did not confirm Bailey's conclusion that HTG females reject male skin in a manner not significantly different from that of $H-2^{b}$ strains. We have previously tested six $H-2^{b}$ strains (Gasser and Silvers 1971b) and in every one a higher proportion of females rejected male grafts than was observed with HTG.

The relatively good response of HTG tends to be inherited as a dominant trait, since $(\mathrm{HTG} \times \mathrm{B} 10 . \mathrm{D} 2) \mathrm{F}_{1}$ females reject male skin in a manner comparable to that of HTG females. To determine whether this difference could be attributed to an $H$-2-linked

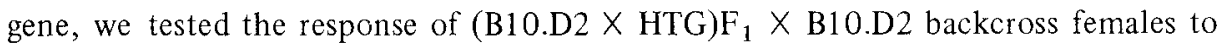
B10.D2 male skin grafts. All mice in this generation should possess the same $H-2 K^{d}$ allelle (and presumably the same allele at the $I r-1$ locus), while one half should possess the $H-2 D^{b}$ allele and the other half $H-2 D^{d}$. If there is a second immune response gene affecting $H-Y$ rejection within $H-2 D$ or distally linked to it, male skin rejection should be linked to $H-2$ in this generation. Twenty-seven of the 54 grafts were rejected within 100 days. The classification of rejectors and nonrejectors according to $H$-2 type is summarized in Table 2. According to these data, there is no correlation between the ability to reject male skin and the $H-2$ type of the female host $\left(\mathrm{X}^{2}=1.21, P=0.25-\right.$ $0.50)$. We conclude therefore that the $H-2 D$ locus is not involved in the immune response difference between HTG and B10.D2 mice.

There also was no correlation between the ability to reject male skin and the genotype at the agouti coat color locus. Of the 27 rejectors, 14 were agouti and 13 were nonagouti, while the 27 nonrejectors consisted of 13 agouti and 14 nonagouti mice. Therefore it does not appear that the $I r-2$ locus, which is linked to agouti (Gasser 1969), is involved in this system.

Response to Ea-l by YBR and B10.D2 Mice. As previously reported (Gasser and Shreffler 1972), strains YBR and B10.D2 appear to differ by a single dominant gene that controls the ability to make agglutinating antibodies to $E a$ - 1 . Since both of these strains possess the $H$-2d chromosome, this immune-response gene apparently is not an allele of the $I r$ - 1 locus. To determine whether this gene is an allele of the $I r-2$ locus, we used YBR mice which are heterozygous for the lethal yellow $\left(A^{y}\right)$ gene, an allele of the agouti locus. Yellow (YBR X B10.D2)F $\mathrm{F}_{1}$ mice genotypically $A y_{a}$ were 
Table 1. Responses of HTG, B10.D2 and (HTG X B10.D2)F 1 Females to Male Skin Grafts

\begin{tabular}{llllll}
\hline & & \multicolumn{3}{c}{ Cumulative Fraction Rejected by } \\
\cline { 3 - 6 } Female Recipients & \multicolumn{1}{c}{ Male Donors } & $\begin{array}{l}0-25 \\
\text { days }\end{array}$ & $\begin{array}{c}26-50 \\
\text { days }\end{array}$ & $\begin{array}{c}51-75 \\
\text { days }\end{array}$ & $\begin{array}{c}76-100 \\
\text { days }\end{array}$ \\
\hline HTG & HTG & $3 / 11$ & $4 / 11$ & $5 / 11$ & $6 / 11$ \\
B10.D2/new & B10.D2/new & $1 / 18$ & $2 / 18$ & $2 / 18$ & $2 / 18$ \\
$($ HTG X B10.D2)F 1 & (HTG X B10.D2)F & $9 / 14$ & $10 / 14$ & $11 / 14$ & $11 / 14$ \\
$($ HTG X B10.D2)F 1 & B10.D2 & $3 / 14$ & $4 / 14$ & $4 / 14$ & $6 / 14$ \\
\hline
\end{tabular}

Table 2. Distribution of Male Skin Graft Rejectors and Nonrejectors in the $($ B 10.D2 $\times$ HTG $) F_{1} \times$ B10.D2 Generation According to H-2 Typea

\begin{tabular}{lccc}
\hline \multicolumn{1}{c}{ Response } & $H-2 \mathrm{~g} / H-2^{\mathrm{d}}$ & $H-2 \mathrm{~d} / H-2^{\mathrm{d}}$ & Total \\
\hline Rejected Skin Graft & 9 & 18 & 27 \\
Did not reject skin graft & 14 & 13 & 27 \\
\hline
\end{tabular}

${ }^{\mathrm{a}} \mathrm{H}-2$ typing was performed by both the PVP hemagglutination and by the cytotoxic absorption technique.

Table 3. Distribution of Responders and Nonresponders to Ea-1 in the (B10.D2 $\times$ YBR)BC 1 Generation According to Agouti Phenotype

\begin{tabular}{ccc}
\hline Generation & Responders & Nonresponders \\
\hline$(\mathrm{B} 10 . \mathrm{D} 2 \times \mathrm{YBR}) \mathrm{BC}_{1} A y_{a}$ & 4 & 9 \\
$\left(\mathrm{~B} 10 . \mathrm{D} 2 \times \mathrm{YBR} \mathrm{BC}_{1} a a\right.$ & 5 & 10 \\
\hline $\mathrm{a}^{2}=0.06 ; P=.75-.90$ & &
\end{tabular}

mated with B10.D2/new mice to produce the first backcross generation. Thirteen of these $\mathrm{BC}_{1}$ mice were yellow $\left(A^{y} a\right)$ and 15 were black nonagouti (aa). The distribution of responders and nonresponders according to agouti phenotype is shown in Table 3 . There was no correlation between ability to respond to $E a-l$ and the agouti phenotype, so the Ir gene segregating in this cross is not linked to agouti and therefore is not an allele of the $I r-2$ locus.

Response to Ea-1 by Strain HTG. Since a gene that is linked to $H-2$ is known to be involved in the response to $E a-1$ (Gasser and Shreffler 1972), we examined the $H$-2-recombinant strain HTG to determine the site within the $H$-2 region that influences 
anti-Ea-1 antibody production. Fifteen HTG mice received multiple injections of erythrocytes from wild-derived $E a-1^{b}$ mice and all 15 produced agglutinating antibodies. All $13(\mathrm{YBR} \times \mathrm{HTG}) \mathrm{F}_{1}$ mice initially injected with $E a^{-1}{ }^{a}$ cells failed to make agglutinating antibodies to this antigen. The parents of these 13 animals had not been tested for response to $E a-l$ and we thought there might be genetic heterogeneity within the YBR or HTG strains. Therefore YBR and HTG mice which were shown to be responders to $E a-1$ antigens, were mated to produce another $F_{1}$ population. When 18 of these animals were tested, all proved to be nonresponders to $E a-1$. These data, as well as the results obtained with both backcross generations and an $F_{2}$ population, are shown in Table 4.

Since the HTG strain possesses the agouti $(A)$ allele and YBR is a nonagouti $(a)$ strain, it was possible to test for linkage to agouti in this cross. As shown in Table 5, the genes controlling responsiveness to $E a-l$ and agouti coat color did not segregate

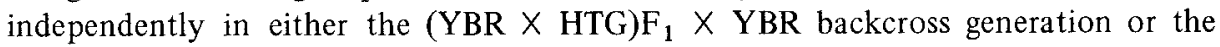
$(\mathrm{YBR} \times \mathrm{HTG}) \mathrm{F}_{2}$ generation. We conclude therefore that the major gene causing $\left(\mathrm{YBR} \times \mathrm{HTG} \mathrm{F}_{1}\right.$ hybrids to be nonresponders is linked to the agouti gene obtained from the HTG parent. Since $I r-2$ is linked to agouti and the dominant allele at this locus is associated with nonresponsiveness (Gasser 1969), it is most likely that HTG possesses the nonresponder gene at the Ir-2 locus. That HTG mice are able to produce antibodies to $E a-1$ can only be attributed to an epistatic effect of background genes.

The data shown in Table 4 cannot be explained easily on the basis of single gene segregation. To determine whether the $I r-1$ locus might also be involved in this system, mice of the $(\mathrm{YBR} \times \mathrm{HTG}) \mathrm{F}_{1} \times \mathrm{HTG}$ generation were typed for $H$-2. Of 39 animals tested, 9 were responders and 30 were nonresponders. As shown in Table 6, there was no correlation between $H-2$ type and responsiveness to $E a-1$ in this generation. Therefore the gene (or genes) other than $I r-2$ that appeats to be involved in this system is (or are) not linked to $H-2$. Furthermore the original goal of this experiment, which was to study the effect of $H$-2-recombinant chromosomes on the $H$-2-linked response to $E a-1$, could not be achieved by studying this strain combination.

Table 4. Segregation Data for Parental, $F_{1}, F_{2}$ and Backcross Generations in YBR and HTG Strains

\begin{tabular}{lcc}
\hline \multicolumn{1}{c}{ Generation } & Responders & Nonresponders \\
\hline YBR & 17 & 7 \\
HTG & 15 & 0 \\
$($ YBR $\times$ HTG $) F_{1}$ a & 0 & 13 \\
$($ YBR $\times$ HTG $) F_{1}$ b & 0 & 18 \\
$($ YBR $\times$ HTG $) F_{1} \times$ HTG & 17 & 30 \\
$($ YBR $\times$ HTG $) F_{1} \times$ YBR & 16 & 22 \\
$($ YBR $\times$ HTG $) F_{2}$ & 13 & 29 \\
\hline
\end{tabular}

aln this experiment the YBR and HTG parents were not immunized.

bThe YBR and HTG parents of the hybrid mice in this experiment were immunized and all were shown to be good responders to $\mathrm{Ea}-1$ antigens. 
Table 5. Distribution of Responders and Nonresponders to Ea-1 in the (YBR $X$ HTG)BC $C_{1}$ and $F_{2}$ Generations According to Agouti Phenotype

\begin{tabular}{|c|c|c|c|c|c|c|}
\hline \multirow[b]{2}{*}{ Generation } & \multicolumn{2}{|c|}{ Agouti } & \multicolumn{2}{|c|}{ Nonagouti } & \multirow[b]{2}{*}{$\chi^{2}$} & \multirow[b]{2}{*}{$P$} \\
\hline & $\begin{array}{l}\text { Respond- } \\
\text { ders }\end{array}$ & $\begin{array}{l}\text { Nonre- } \\
\text { sponders }\end{array}$ & $\begin{array}{l}\text { Respond- } \\
\text { ders }\end{array}$ & $\begin{array}{l}\text { Nonre- } \\
\text { sponders }\end{array}$ & & \\
\hline$\underset{\times \text { YBR }}{\left(\mathrm{YBR}_{\mathrm{YBT}} \times \mathrm{H}_{1}\right.}$ & 0 & 19 & 16 & 3 & 24.28 & $<.005$ \\
\hline$(\mathrm{YBR} \times \mathrm{HTG}) \mathrm{F}_{2}$ & 5 & 24 & 8 & 5 & 6.30 & $<.025$ \\
\hline
\end{tabular}

Table 6. Distribution of Responders and Nonresponders to Ea-1 in the

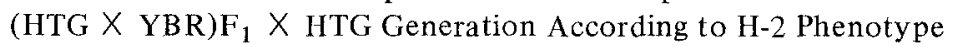

\begin{tabular}{lcc}
\hline Generation & $H-2^{\mathrm{d}} / H-2 \mathrm{~g}$ & $H-2 \mathrm{~g} / H-2 \mathrm{~g}$ \\
\hline Responders & 5 & 4 \\
Nonresponders & 20 & 10 \\
\hline
\end{tabular}

H-2 typing was based upon the presence or absence of a reaction with an anti-H-2.4 antiserum in the PVP hemagglutination technique.

To confirm that the antibody produced by strain HTG was specific for $E a-1$, a preliminary in vivo absorption experiment was performed. Sera from four HTG animals that possessed an anti-Ea- $l^{a}$ titer of approximately $1: 32$ were pooled and diluted $1: 1$ in saline. Two-tenths milliliters of this diluted antiserum was injected into each of three wild $E a-I^{a}$ recipients and three $\mathrm{C} 57 \mathrm{BL} / 10$ recipients. Three hours later the recipients were bled and their titers determined. The serum from each of the wild $E a-I^{a}$ recipients was completely negative for anti-Ea- $I^{a}$ activity, while each of the $\mathrm{C} 57 \mathrm{BL} / 10$ recipients had an anti-Ea-1a titer of $1: 4$. Allowing for the dilution in saline and the dilution in the blood volume of recipients, there apparently was no absorption by the $\mathrm{C} 57 \mathrm{BL} / 10$ control recipients, while the wild $E a-I^{a}$ recipients completely absorbed the antibody activity.

\section{Discussion}

In these experiments an attempt was made to analyze minor genetic factors that influence the reactivity of inbred mice to the H-Y histocompatibility antigen and the Ea-1 erythrocyte antigen. We have shown that the relatively rapid rejection of male skin by strain HTG as compared to that of B10.D2 cannot be explained by an $\mathrm{H}-2$ linked gene. This resolves a conflict that arose in Bailey's experiments in which he attempted to localize the major gene influencing $\mathrm{H}-\mathrm{Y}$ rejection within the $\mathrm{H}-2$ locus (Bailey 1971). Bailey's observations are now consistent with the interpretation that the $H$-2-linked gene determining male skin rejection is either distally linked to or within the region containing $K$ and $I r-1$. 
Two genetic loci controlling the response to $E a-1$ have been described previously. Strains BALB and CBA possess a dominant nonresponder allele at the $I r$ - 2 locus, which is linked to agouti (Gasser 1969). In a cross in which neither parental strain possesses the dominant nonresponder allele (YBR $\times$ B10), responsiveness is dominant and is determined by more than one gene (Gasser 1970; Gasser and Shreffler 1972). One of these genes is linked to the $H-2$ complex (Gasser and Shreffler 1972), and we have now shown that the other gene is not linked to agouti. The last named gene therefore represents the third locus to be identified that influences the antibody response to $E a-1$.

Our studies on the response to $E a-l$ depended upon the principle that, regardless of how many genes a species possesses which influence a particular trait, as long as two strains that differ by only one or two loci can be compared, simple Mendelian segregation can be observed. Thus although at least three loci influence the response to $E a-l$, the segregation of only one of these can be studied when YBR is crossed with BALB or CBA (Gasser 1969) and another one segregates when YBR is crossed with B10.D2 (Gasser and Shreffler 1972). When YBR is crossed with B10, the data obtained are compatible with segregation at two loci (Gasser and Shreffler 1972).

A new phenomenon has been observed in that the mating of two responder strains (YBR and HTG) can produce an $\mathrm{F}_{1}$ generation of complete nonresponders. The most intriguing feature of this system is that strain HTG was shown to possess the dominant nonresponder allele at the Ir-2 locus. Whatever effect this gene causes, it seems to be masked by the background genes of strain HTG when these genes are present in a homozygous state. One might explain this by postulating the existence of an interaction antigen in the $\mathrm{F}_{1}$ hybrid which either cross-reacts with $E a-1$ or causes tolerance at the T-cell level (Ruben et al. 1973). Whether this is indeed the case remains to be determined.

\section{Acknowledgments}

We thank Mrs. Brigitte Koeberlein for excellent technical assistance. This study was supported by National Institutes of Health grant CA-15146.

\section{References}

Bailey, D. W. and Hoste, J.: A gene governing the female immune response to the male antigen in mice. Transplantation 11:404-407, 1971.

Bailey, D. W.: Allelic forms of a gene controlling the female immune response to the male antigen in mice. Transplantation 11:426-428, 1971.

Benaceraf, B., Bluestein, H. G., Green, I. and Ellman, L.: Specific immune response genes of guinea pigs. In D. B. Amos (ed.): Progress in Immunology T; pp. 485494, Academic Press, New York, 1971.

Billingham, R. E.: Free skin grafting in mammals. In R. E. Billingham and W. K. Silvers (eds.): Transplantation of Tissues and Cells; pp. 1-26, Wistar Institute Press, Philadelphia, 1961.

David, C. S. and Shreffler, D. C.: Adaptation of the 51 Cr cytotoxic assay for rapid $H-2$ classifications on peripheral blood cells. Transplantation 13:414-420, 1972. 
Gasser, D. L.: Genetic control of the immune response in mice. I. Segregation data and localization to the fifth linkage group of a gene affecting antibody production. J. Immunol. 103:66-70, 1969.

Gasser, D. L.: Genetic control of the immune response in mice. II. A two-way selection experiment for specific immunologic competence. J. Immunol. 105:908-911, 1970.

Gasser, D. L. and Silvers, W. K.: Genetic control of the immune response in mice. III. An association between $H-2$ type and reaction to $H^{-} Y$. J. Immunol. 106:875876,1971 a.

Gasser, D. L. and Silvers, W. K.: The genetic basis of male skin rejection in mice. Transplantation 12:412-414, $1971 \mathrm{~b}$.

Gasser, D. L. and Shreffler, D. C.: Involvement of H-2 locus in a multigenicallydetermined immune response. Nature New Biol. 235:155-156, 1972.

Ruben, T. J., Chiller, J. M. and Weigle, W. O.: The cellular basis of cross-tolerance. J. Immunol. 111:805-810, 1973. 